\title{
Specyfika przedsiębiorstw zaawansowanych technologii (high-tech)
}

\author{
Milena Ratajczak-Mrozek
}

\section{Wprowadzenie}

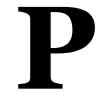

rzedsiębiorstwom zaawansowanych technologii (high-tech) przypisuje się istotną rolę w ksztaltowaniu konkurencyjnej gospodarki, a ich znaczenie stale rośnie. Celem artykułu jest usystematyzowanie pojęć związanych $\mathrm{z}$ tematyką przedsiębiorstw zaawansowanych technologii oraz określenie ich specyfiki na tle przedsiębiorstw reprezentujących tzw. branże tradycyjne.

\section{Przedsiębiorstwa zaawansowanych technologii - nazewnictwo i nomenklatura}

W zagranicznej literaturze przedmiotu przedsiębiorstwa zaawansowanych technologii określane są najczęściej mianem high-tech lub high-technology. W polskich publikacjach naukowych stosowane są dość liczne tłumaczenia tego pojęcia (np. - przedsiębiorstwa zaawansowanych technologiii1) - wysokich technologii2) - wysokiej techniki3) - oparte na nowych technologiach4) • handlujące towarami zaawansowanymi pod względem technologicznym ${ }^{5}$. Równie często $\mathrm{w}$ polskich publikacjach używa się bezpośrednio angielskiej nazwy high-tech. W artykule przyjęto zamienne stosowanie terminów przedsiębiorstwa zaawansowanych technologii oraz high-tech. Określenie wysokie technologie, stosowane przez Główny Urząd Statystyczny, wydaje się być zbyt bezpośrednio thumaczone $\mathrm{z}$ języka angielskiego i tym samym niepoprawne językowo.

Zgodnie $\mathrm{z}$ propozycją zawartą $\mathrm{w}$ raporcie Komisji Europejskiej6) przedsiębiorstwa high-tech są to przedsiębiorstwa wysokoinnowacyjne $\mathrm{i} / \mathrm{lub}$ intensywnie działające w obszarze badań i rozwoju i/lub wykorzystujące kompleksową technologię produkcji. Z kolei Główny Urząd Statystyczny definiuje zaawansowaną technologię jako dziedziny i wyroby odznaczające się wysoką intensywnością badawczorozwojową, a ponadto charakteryzujące się wysokim poziomem innowacyjności, krótkim cyklem życia wyrobów i procesów, szybką dyfuzją innowacji, wzrastającym zapotrzebowaniem na wysoko wykwalifikowany personel (szczególnie w zakresie nauk technicznych i przyrodniczych), dużymi nakładami kapitałowymi, wysokim ryzykiem inwestycyjnym (i szybkim „starzeniem się” inwestycji), ścisłą współpracą naukowo-techniczną (w obrębie poszczególnych krajów i na arenie międzynarodowej pomiędzy przedsiębiorstwami i instytucjami badawczymi) oraz wzmagającą się konkurencją $\mathrm{w}$ handlu międzynarodowym ${ }^{7)}$. Przytoczone definicje niewątpliwie ujmują szerokie spektrum omawianej problematyki, ale $\mathrm{z}$ drugiej strony praktycznie uniemożliwiają wyraźne wyznaczenie grupy przedsiębiorstw, które powinny stanowić obiekt badań z zakresu zaawansowanych technologii.

$\mathrm{Z}$ uwagi na nakreślony powyżej problem, $\mathrm{w}$ badaniach dotyczących przedsiębiorstw high-tech dominuje ujęcie branżowe (przedmiotowe) - identyfikowane $\mathrm{i}$ porównywane są przedsiębiorstwa reprezentujące wybrane, wymienione na podstawie określonych miar branże. Aplikując to rozwiązanie, trzeba być jednak świadomym, że nie jest ono pozbawione wad. Kategoria branży jest na tyle szeroka, że w jej skład mogą wchodzić indywidualne przedsiębiorstwa o różnym stopniu zaawansowania wykorzystywanej technologii i innowacyjności. Istnieje też możliwość występowania zaawansowanych technologicznie przedsiębiorstw poza zakwalifikowanymi branżami.

Istnieją różne podejścia do metodologii klasyfikacji dziedzin zaawansowanej technologii. Do najistotniejszych należą kryteria i nomenklatury określone przez organizacje międzynarodowe - OECD oraz Eurostat. Wytyczne OECD zawarte są w tzw. opracowaniach bazowych, serii międzynarodowych podręczników, czyli powszechnie przyjętych zaleceń metodologicznych (Frascati Family Manuals). Jednakże problematyka dotycząca przedsiębiorstw high-tech jest $\mathrm{w}$ nich przedstawiona $\mathrm{w}$ sposób fragmentaryczny. W podręczniku Frascati Manuat8) stwierdza się wręcz, że międzynarodowe wytyczne $\mathrm{w}$ zakresie metodologii high-tech nie istnieją, ale metody OECD wykorzystywane do klasyfikacji branż względem poziomu technologii i wynikające $\mathrm{z}$ tego klasyfikacje są przedstawione $\mathrm{w}$ opracowaniu (workirtg paper) T. Hatzichronoglou'9).

Klasyfikacja OECD jest sporządzona na podstawie wielkości nakładów (bezpośredniej i pośredniej) na badania i rozwój $\mathrm{w}$ stosunku do wartości dodanej poszczególnych branż. Obejmuje ona cztery grupy - zaawansowaną technologię (high-technology), średnio zaawansowaną technologię (medium-high-technology), średnioniską technologię (medium-low-technology) oraz niską technologię 
(low-technology). Zgodnie $\mathrm{z}$ tą klasyfikacją do grupy branż zaawansowanych technologii zaliczone są produkcje ${ }^{10)}$ : - sprzętu lotniczego - wyrobów farmaceutycznych • komputerów i maszyn biurowych - sprzętu i aparatury radiowej, telewizyjnej i komunikacyjnej.

Z kolei według wytycznych Eurostatu ${ }^{11)}$, dotyczących sprawozdawczości statystycznej państw członkowskich, kandydujących, stowarzyszonych w Europejskim Stowarzyszeniu Wolnego Handlu (EFTA) oraz stron trzecich, do branż zaawansowanych technologii zaliczane są produkcje: - sprzętu lotniczego • wyrobów farmaceutycznych • komputerów i maszyn biurowych - sprzętu i aparatury radiowej, telewizyjnej i komunikacyjnej • instrumentów naukowych i precyzyjnych.

Dodatkowo, w odróżnieniu od klasyfikacji OECD, w nomenklaturze Eurostatu zostały wyróżnione usługi zaawansowanych technologii (high-tech knowledge-intensive services, high-tech KIS). W ich ramach wymienia się: • pocztę i telekomunikację

- informatykę • badania i rozwój.

Co ciekawe, tak jak publikacje Eurostatu cechuje spójność i stosowana jest w nich ta sama, przedstawiona powyżej nomenklatura, tak w przypadku publikacji wydawanych pod egidą OECD tej spójności nie ma. Na przykład w OECD Science, Technology and Industry Outlook 2006 przyjmuje się pięć (zamiast czterech) branż zaawansowanych technologii, natomiast $\mathrm{w}$ OECD Science, Technology and Industry Scoreboard 2007 nie dość, że wymienia się pięć branż high-tech, to ponadto uwzględnia się usługi oparte na wiedzy (knowledge-intensive services), bez wyróżnienia tych usług, które są zaawansowane technologicznie ${ }^{12}$.

W kontekście przytoczonych nomenklatur należy zauważyć, że nie wszystkie z wymienionych we wstępie tłumaczeń angielskiego terminu high-tech powinno się traktować jako synonimy. Zakres pojęcia przedsiębiorstw zaawansowanych technologii jest relatywnie szeroki i dotyczy podmiotów reprezentujących większą liczbę branż, tymczasem nowe technologie można zagregować w pięciu podstawowych grupach ${ }^{13)}$, jakimi są technologie informacyjne (w tym elektroniczne, informatyczne i komunikacyjne), biotechnologie oraz technologie materiałowe (np. nanotechnologie), energetyczne i kosmiczne.

Reasumując rozważania dotyczące kwestii metodologicznych, związanych z problematyką przedsiębiorstw high-tech, można postulować definiowanie tej grupy przedsiębiorstw na podstawie przytoczonego ujęcia branżowego. Jako kryterium selekcji uzasadnione wydaje się przyjęcie bardziej spójnej klasyfikacji Eurostatu. Dla delimitacji sektora high-tech zakłada się więc nie tyle homogeniczność produktów, technologii produkcji czy potrzeb, co właściwość produktów i stosowanych procesów, jaką jest stopień zaawansowania technologicznego ${ }^{14)}$.

\section{Zaawansowane technologie a innowacje}

W iele publikacji związanych $\mathrm{z}$ zagadnieniem zaawansowanych technologii $\mathrm{w}$ istocie poświęcona jest innowacyjności przedsiębiorstw. Badania innowacji i innowacyjności oraz dane na ten temat stanowią obecnie obszerną dziedzinę wiedzy, jednak trzeba podkreślić, że przedsiębiorstwa innowacyjne to niekoniecznie przedsiębiorstwa oparte na zaawansowanych technologiach. Innowacje mogą pojawić się w każdej branży gospodarki, czyli także w branżach tradycyjnych (średnioniskiej i niskiej technologii).

W rozumieniu metodologii Oslo Manuat minimalny wymóg do występowania innowacji stanowi, że produkt, proces, metoda marketingowa lub organizacyjna musza być nowe lub znacząco ulepszone dla danej firmy ${ }^{15)}$. Oznacza to, że sprawozdania statystyczne na temat innowacji dotyczą wyrobów i procesów będących nowością już w skali pojedynczego przedsiębiorstwa, przy czym nie podejmuje się kwestii stopnia nowości. Nie w pełni odpowiada to idei zaawansowanych technologii (co jednocześnie nie ujmuje znaczenia innowacyjności dla przedsiębiorstw high-tech).

\section{Charakterystyka przedsiębiorstw high-tech}

$\mathbf{R}$ óżnorodność przedsiębiorstw high-tech powoduje, że ważne jest udzielenie odpowiedzi na pytanie, jaka charakterystyka wyróżnia je na tle przedsiębiorstw reprezentujących branże tradycyjne. Na bazie analizy literatury przedmiotu (m.in. charakterystyki omawianych przedsiębiorstw, wynikającej z przytoczonych wcześniej definicji Głównego Urzędu Statystycznego oraz Komisji Europejskiej) można zaproponować następujace cechy pierwotne przedsiębiorstw zaawansowanych technologii, decydujące o wyraźnej specyfice tej grupy firm:

- wykorzystanie kompleksowej technologii produkcji,

- wysoki poziom innowacyjności wraz z szybką dyfuzją innowacji technologicznych,

- działanie w obszarze badań i rozwoju,

- krótkie cykle życia produktów,

- często jednorodny popyt na produkty oraz działalność na rynkach niszowych.

Dodatkowo należy zaproponować następujące cechy wtórne:

- wysokie kwalifikacje pracowników,

- wysokie ryzyko inwestycyjne,

- duże nakłady kapitałowe wraz z problemem finansowania,

- dużą skłonność do internacjonalizacji działalności.

Przedstawioną charakterystykę celowo podzielono na część główną - pierwotną, przyczynową oraz część drugą - wtórną, która w dużej mierze jest następstwem cech sklasyfikowanych jako główne.

Przedsiębiorstwa zaawansowanych technologii charakteryzuje wykorzystanie kompleksowej technologii produkcji i co się $\mathrm{z}$ tym wiąże konieczność wysokiego poziomu innowacyjności oraz działania w sferze badawczej i rozwojowej. Ponadto produkty i usługi oferowane przez przedsiębiorstwa high-tech są opisywane przez krótkie cykle życia, co jest zdeterminowane procesem szybkiego starzenia się i dewaluacji „stopnia nowości” technologii. Na dodatek, w stosunku do krótkiej obecności na rynku, sam okres rozwoju produktu (czyli również proces badawczo-rozwojowy i innowacyjny) jest relatywnie długi. 
Kolejną właściwością produktów zaawansowanych technologii jest fakt, że na wiele $\mathrm{z}$ nich występuje jednorodny popyt na wielu rynkach. Dzięki temu ich strategie moga być wysoce zestandaryzowane. Oznacza to często działalność na rozproszonych geograficznie specjalistycznych międzynarodowych rynkach niszowych.

Ze względu na krótkie cykle życia produktów, wagę innowacyjności i dużą intensywność prowadzonych prac badawczo-rozwojowych, w przedsiębiorstwach zaawansowanych technologii znaczenia nabieraja wysokie kwalifikacje zatrudnionych $\mathrm{w}$ nich pracowników. Badania potwierdzają ${ }^{16)}$, że brak wykwalifikowanych pracowników reprezentuje jedną $\mathrm{z}$ głównych barier rozwoju europejskich małych i średnich przedsiębiorstw zaawansowanych technologii.

Kolejnym następstwem tych samych charakterystyk pierwotnych jest niepewność i duży poziom ryzyka inwestycyjnego, które wynikają m.in. z charakteru procesów badawczo-rozwojowych $\mathrm{i}$ innowacyjnych, krótkich cykli życia produktów, trudności w oszacowaniu potencjału rynkowego i ryzyka związanego $\mathrm{z}$ zastosowaniem nowej wiedzy. Bezpośrednio $\mathrm{z}$ ryzykiem inwestycyjnym związana jest kwestia wymaganych dużych nakładów kapitałowych $\mathrm{w}$ przedsiębiorstwach high-tech (wyjątek stanowią np. internetowe firmy informatyczne) i problem w finansowaniu ich działalności, co powoduje, że ogromne znaczenie $\mathrm{w}$ odniesieniu do tych przedsiębiorstw odgrywa kapitał wysokiego ryzyka (venture capital).

Ostatnią cechę wtórną przedsiębiorstw zaawansowanych technologii stanowi duża skłonność do internacjonalizacji działalności. Dla przedsiębiorstw high-tech internacjonalizacja nie jest kwestią wyboru, lecz koniecznością, gdyż rynek krajowy kreuje zbyt ograniczony popyt na oferowane przez nie produkty. Badania potwierdzają większe umiędzynarodowienie przedsiębiorstw zaawansowanych technologii $\mathrm{w}$ porównaniu $\mathrm{z}$ przedsiębiorstwami z branż tradycyjnych ${ }^{17)}$. Ponadto to właśnie przedsiębiorstwa high-tech stanowią najczęstszy przykład przedsiębiorstw typu born global, czyli „urodzonych globalistów”, podmiotów, które od momentu powstania czerpią przewage konkurencyjną $\mathrm{z}$ wykorzystania zasobów i sprzedaży produkcji w wielu kraj ach ${ }^{18)}$.

\section{Przedsiębiorstwa zaawansowanych technologii w Polsce}

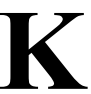

rytyczny przegląd podstawowych danych i wskaźników wykazuje, że na poziomie całej gospodarki obraz zaawansowanych technologii $\mathrm{w}$ Polsce $\mathrm{w}$ porównaniu $\mathrm{z}$ innymi krajami nie jest satysfakcjonujący. Przedsiębiorstwa i cały sektor high-tech nie imponują zarówno pod względem wartości obrotów, produkcji, eksportu i importu, sprzedaży, sytuacji związanej $\mathrm{z}$ działalnością badawczą i rozwojowa, jak i liczby zatrudnionych.

Mimo opisanej negatywnej sytuacji, można również dostrzec duży potencjał niezbędny do dalszego rozwoju przedsiębiorstw high-tech w Polsce. Mocnymi stronami sektora zaawansowanych technologii są: duża liczba przedsiębiorstw oraz wysokie (i większe niż średnio w UE-27) średnioroczne tempo wzrostu w zakresie eksportu, zatrudnienia i liczby patentów high-tech, a także potencjał w zakresie kadry naukowo-badawczej.

W 2004 r. według Eurostatu w Polsce było 14874 przedsiębiorstw produkcyjnych zaawansowanych technologii (high-tech manufacturersy ${ }^{19)}$. Pod tym względem Polska zajmowała wysoka, czwarta pozycję wśród krajów członkowskich Unii Europejskiej (UE-27). Problemem sektora zaawansowanych technologii jest więc nie tyle niewielka liczba przedsiębiorstw high-tech, lecz ich nieduża siła rynkowa. Tak duża liczba przedsiębiorstw wynika bowiem przede wszystkim z wielkości samych podmiotów - są to głównie mikro-, małe i średnie przedsiębiorstwa.

Należy podkreślić, że wśród polskich przedsiębiorstw zaawansowanych technologii są także prawdziwi liderzy, którzy produkują prawdziwie unikatowe $\mathrm{w}$ skali światowej wyroby, prowadzą intensywne prace badawcze i współpracują z ośrodkami naukowymi. Na przykład Optopol Technology SA jest producentem nowoczesnych urządzeń diagnostycznych wykorzystywanych w okulistyce; Vigo System SA produkuje niechłodzone fotonowe detektory podczerwieni i kamery termowizyjne; Zakłady Elektronowe Lamina SA oferują magnetrony, a Solaris Laser SA - laserowe urządzenia do znakowania i kodowania. Ponadto trzeba wspomnieć o sile rodzimych przedsiębiorstw $\mathrm{z}$ branży IT (m.in. Comarch SA). Z kolei największą i najbardziej znaną firmą biotechnologiczną w Polsce jest spółka Bioton SA - jeden $\mathrm{z}$ czterech światowych producentów insuliny rekombinowanej. Pozostali liderzy z branży to Adamed Sp. z o.o. (prowadzi m.in. badania nad nowym lekiem w terapii cukrzycy oraz terapii przeciwnowotworowej) oraz Celon Pharma Sp. z o.o. (m.in. wykorzystuje nową technologię nagrodzoną Noblem w dziedzinie medycyny).

\section{Podsumowanie}

D rzedsiębiorstwa zaawansowanych techno1 logii bazujace na wiedzy stanowią jeden z głównych czynników rozwoju całej gospodarki i $\mathrm{z}$ tego powodu stanowią bardzo ważny obiekt badań, traktowany z coraz większą dociekliwością. Jednakże wciąż brak pełnej spójności charakteryzującej ten obszar nauki. Jest to o tyle istotne, że to właśnie kompleksowe badania i teoretyczne uogólnienia powinny stanowić bazę do tworzenia polityki skutecznie wspierającej rozwój przedsiębiorstw zaawansowanych technologii.

dr Milena Ratajczak-Mrozek Katedra Marketingu Międzynarodowego Uniwersytetu Ekonomicznego w Poznaniu

\section{PRZYPISY}

1) Por. M. GURBAŁA, Przemyst zaawansowanej technologii $w$ Polsce, „Kwartalnik Nauk o Przedsiębiorstwie” nr 3/2007. 2) Por. K. KOZIOŁ, Cele $i$ bańery działalności innowacyjnej polskich przedsiębiorstw wysokiej technologii, „Przegląd Organizacji” nr 5/2006; K. WŁOSIŃSKI, A.M. SZERENOS, Klastry 
wysokotechnologiczne na Mazowszu - wyniki badań, „Organizacja i Kierowanie" nr 3/2006.

3) Por. G. NIEDBALSKA i inni, Definicje pojęć z zakresu statystyki nauki $i$ techniki, Główny Urząd Statystyczny, Warszawa 1999, s. 98.

4) Por. L. CICHOWSKI, Male $i$ średnie przedsiębiorstwa a innowacje, w: T. ŁUCZKA (red.), Male i średnie przedsiębiorstwa, Wydawnictwo Politechniki Poznańskiej, Poznań 2005, s. 123.

5) Por. Z. WYSOKIŃSKA, Konkurencyjność $w$ międzynarodowym $i$ globalnym handlu technologiami, Wydawnictwo Naukowe PWN, Warszawa, Łódź 2001, s. 173.

6) Ibidem, s. 61 .

7) Observatory of European SMEs 2002- High-tech SMEs in Europe, European Commission, Brussels 2003, s. 7.

8) G. NIEDBALSKA i inni, Definicje..., op. cit., s. 98.

9) Proposed Standard Practice for Surveys of Research and Experimental Development - Frascati Manual, 6th edition, OECD 2002, s. 206.

10) T. HATZICHRONOGLOU, Revision of the High-Technology Sector and Product Classification, „OECD Science, Technology and Industry Working Papers" 1997/2, OECD Publishing 1997.

11) Ibidem, s. 6 .

12) High-tech Industry and Knowledge-Intensive Services. Reference Metadata in Euro SDMX Metadata Structure, http://epp.eurostat.ec.europa.eu/cache/ITY_SDDS/EN/ htec_esms.htm (data odczytu: 14.09.2010).

13) OECD Science, Technology and Industry Outlook 2006,

OECD 2006, s. 206; OECD Science, Technology and Industry

Scoreboard 2007, OECD 2007, ss. 210, 220.

14) Więcej na temat definicji i metodologii przedsiębiorstw high-tech zob. M. RATAJCZAK-MROZEK, Sieci biznesowe a przewaga konkurencyjna przedsiębiorstw zaawansowanych technologii na rynkach zagranicznych, Uniwersytet Ekonomiczny w Poznaniu, Poznań 2010.

15) OECD Proposed Guidelines for Collecting and Interpreting Innovation Data - Oslo Manual, 3rd edition, OECD/EU/ Eurostat 2005, ss. 46, 48 .

16) Observatory..., op. cit., s. 8 .

17) Ibidem, s. 24.

18) B.M. OVIATT, P.P. McDOUGALL, Towards a Theory of International New Ventures, „Journal of International Business Studies" 1994, vol. 25, no. 1, s. 49.

19) Dane według: Science, Technology and Innovation in Europe (2009 edition), European Commission, Eurostat, European Communities 2008, s. 152.

\section{Summary}

The aim of the article is systematization of terminology concerning high-technology companies and defining their specificity compared to companies representing traditional industries. The article includes review of terminology concerning high-tech companies and main classifications of high-tech sector. Additionally following characteristics of high-tech companies are defined: complex production technology, short product life cycles, often homogeneous demand for products and activity on niche markets, employees with specialized qualifications, high investment risk, high capital expenditure, tendency to activity's internationalization. At the conclusion of the article status of high-tech industry in Poland is described and a few examples of Polish companies - leaders in high-tech industry are given. 